\title{
Serum levels of endothelial monocyte activating polypeptide-II in type 1 diabetes patients with microangyopathy and arterial hypertention.
}

\author{
Mogylnytska L.A., MD., PHD ${ }^{1}$, Mankovsky B. ${ }^{2}$ \\ ${ }^{1}$ Khmelnitsky regional hospital, 1 , Pilotska str., Khmelnytsky, Ukraine \\ ${ }^{2}$ National Medical Academy for Postgraduate Education, Kiev, Ukraine
}

Aim. To determine the serum level of EMAP-II as a marker of endothelial dysfunction in type 1 diabetic patients with microangiopathy, to study of the association of arterial hypertension and the level of this factor, its relationship with the endothelium-dependent dilatation and other risk factors for cardiovascular disease.

Materials and methods. We examined 23 type 1 diabetic patientwith microangiopathy and arterial hypertension, 10 type 1 diabetic patient with microangiopathy without hypertension and

28 healthy control subjects. Serum levels of EMAP-II were determined by immunoenzyme assay. Endothelium-dependent dilatation was estimated by Celermajers metod. The data were presented as means $\pm S D$. Statistical analysis was performed using the t-Student, Spearman's rank correlation coefficient, multiple regression analysis.

Results. We found an increased serum level of EMAP-II in type 1 diabetic patients with microangiopathy and arterial hypertension compared to control group $(5,23 \pm 1,66 \mathrm{ng} / \mathrm{ml}$ and $1,25 \pm 0,76 \mathrm{ng} / \mathrm{ml}$ respectively, $p<0,01)$, and in type 1 diabetic patients with microangiopathy and arterial hypertension compared to group of diabetic patients without hypertension

$(5,23 \pm 1,66 \mathrm{ng} / \mathrm{ml}$ and $3,63 \pm 1,9 \mathrm{ng} / \mathrm{ml}$ respectively, $p<0,01)$.

Also, the level of EMAP-II correlated with key markers of carbohydrate and lipid metabolism, and inversely correlated with endothelium-dependent dilatation $(p<0,05)$. Significant factors that affect on the serum level of EMAR-II in type 1 diabetes patients with microangiopathy and arterial hypertension were $\mathrm{HbA1c}$, total cholesterol and triglycerides, also systolic and diastolic blood pressure, and in non-hypertensive patients $\mathrm{HbA1c}$.

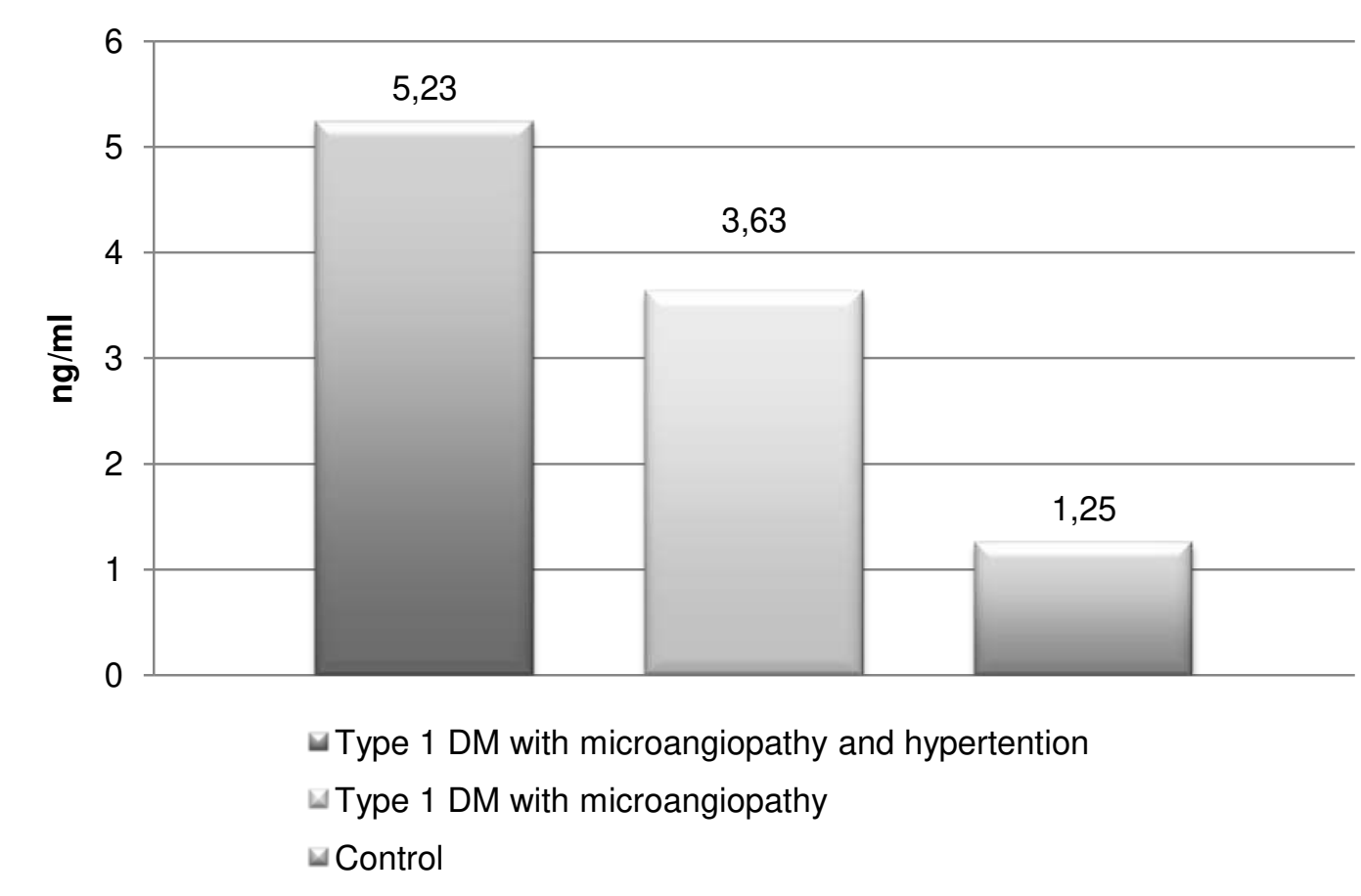

Conclusion. The revealed changes of EMAP-II serum levels could reflect an endothelial dysfunction in patients with type 1 diabetes with microangiopathy and arterial hypertension. Arterial hypertension, hyperglycemia, dyslipidemia appear to be significant contributing factor to the elevation of EMAP-II. 
